Author's copy. The article has been published in Space and Culture, doi:10.1177/1206331216631290. For citation, please use the original.

\title{
Living together in the topological home
}

\section{Kirsi Pauliina Kallio}

\begin{abstract}
The paper discusses the mundane politics of familial life from children's perspectives and portrays the home as a relational space of subject formation and a context of everyday politics. The approach is based on an Arendt-inspired understanding of politics and a topological conception of spatiality that appreciates the intensity, frequency, and significance of social relations as being constitutive of political life. The paper views the home as spatially finite yet open-ended in scale, resting upon and shifting by intersubjectively established and subjectively experienced spatial attachments. It therefore appears as a multi-faceted context of development and practice that consists of people, places, and things near and far, of kith and kin. The empirical analysis, based on an ethnographic research project, explores the plurality of children's familial spatial attachments, the particularity of their familial subjectivities and their active and developing political agencies in the 'topological home'.
\end{abstract}

\section{Introduction}

In thinking about children's lived worlds, among the first things that come to mind are the home and the family. In research these concepts are frequently coupled, which any scholarly database search will confirm. For instance, Google Scholar gives 3640000 hits for 'children'. Of these, 3150000 include references to 'home', 3040000 to 'family', and 2860000 to both. ${ }^{\text {i }}$ The significance of the home and the family are only underlined if contested. When children are provided substitute care they are placed in 'children’s homes', 'group homes', or 'foster homes' with 'host families’ (Berrick et al., 1993; Vanderbeck, 2008). When urban outdoor environments become children's everyday living space, the street may be seen as their 'home' and the people 
who share it their 'family' (Bar-On, 1997; Ursin, 2011). These linguistic formulations imply that, despite the situation, children must have a home and a family to get by.

Yet what is the child's home and family, who belongs to it and where the home resides are not as self-evident as one might first think. Children’s lived worlds are built through conceived and experienced connections with the people and in places accessible and approachable to them, as for example the studies by Barker (2012), Kullman (2012), Bartos (2013), and Strandell (2013) demonstrate (see also Bunnell et al., 2012). Youthful spatial attachments are established in the practice of everyday life that may be concentrated around the physical family home and kinship relations, but they may also expand in all kinds of directions. Children move for many reasons in their familial lives, including: fundamental (migration, adoption, custody, moving house); daily (school, hobbies, work, peers, outdoor activities); occasional (vacation journeys, familial gatherings, friend family visits, overnight stays); and virtual (social networks, live-roleplay worlds, popular cultural sites) movement. The members, locations, constituents, and practices of families and the home are therefore somewhat variable and unpredictable.

This plurality came to the fore in my recent study, in which I asked some 129 'early youth' (11-16 year-olds) to explain and locate their spatial attachments. When talking about their homes and familial lives, they made numerous spatial references that did not follow common paths. Included were conventional portrayals - 'the home is where the house is'- that reproduced established notions of home and family. Yet many of the place-based biographies contest this picture by making no clear separation between familial and other life, or home and away, and instead they weave family and home indivisibly into the fabric of daily life. 'The familial' springs up here and there but wanes as other aspects of life emerge and occupy the stage, and it lacks in places that beg its presence, yet appears in places where you would not expect it, in ways 
surprising, touching, and striking. Besides physical location and metric distance, these biographies disclose intense and distinctive social relations, portraying networks, clusters, and fluctuating associations belonging to what Mason and Tipper (2008, p.443) call "the ordinary complexity of kinship”.

Another empirical finding concerns my participants' active agency in shaping their familial geographies. Many of the kids did not present themselves as members of their families but as active agents in them, possessing the capacity to influence the 'what, who and where' of their families. These observations echo the feminist work that has thoroughly politicized women's impact on their familial lives (e.g. Abel and Nelson, 1990; Mitchell et al., 2003; Dyck, 2005; Muños González, 2005). The question of political agency extends to the young family members’ efforts: Why would they be less significant? If the personal is political, children's familial life seems an obvious context of politics as they are even more strongly bound by the family institution than women in the contemporary world; at least in the Euro-American realities. Should we not therefore appreciate children as political agents when they act for and against the matters that they find important in their familial lives?

As a tentative attempt to engage with these themes, this paper sets out to explore home as a relational context of living; one that is not reducible to fixed locations but that contains both lasting and fleeting elements that build and transform through experiential socio-spatial attachments. Seizing the "opportunity for geographers to think again about how it is that events elsewhere seem to be folded or woven into the political fabric of daily life” (Allen 2011, p.318), I analyze the familial spatial attachments brought up by my young participants through a topological lens. My aim is twofold. First, to display that home is not a static physical spot that can be placed on a map, and instead approach it as a much richer and less coherent dynamic 
context of living. Second, to show that the spatial attachments that children actively create in their mundane practices are influential in the geographies of their homes.

\section{Home as a topological venue of living together}

The concept of topology has its origins in mathematical sciences where it implies objects’ properties as definitive of continuity, rather than their exact shape. As a social theoretical concept it sets out to challenge established ways of thinking about spatiality. Topology is often contrasted with topography where distance in Euclidean space and hierarchical spatial scales are pertinent. Topological rationale, instead, emphasizes the intensity of social relations and ties of belonging as constitutive of proximity. From this perspective, fixed and general relations between places, things, and people cease to dominate what is meaningful, making way for contextually qualified transformable spatial attachments.

The present interdisciplinary social scientific scholarship encompasses multiple ways of understanding and using topology. Topological and topographical approaches may be juxtaposed as alternate ways of conceiving the world in spatial terms, underlining the analytical power of the first approach (e.g. Amin, 2004; Thrift, 2006; Lury, 2013). Topology may also be posited as a major concept that includes various (potential) forms of spatiality, e.g. territorial, networked, and fluid (e.g. Mol and Law, 1994; Shields, 1997, 2013; Häkli, 2008; Martin and Secor, 2013), or topology and topography may be seen as simultaneous spatial realities in the life of societies, institutions, and people (e.g. Desforges et al., 2005; Allen, 2011; Giaccaria and Minca, 2011; Paasi, 2011; Secor, 2013).

Leaning on the latter perspectives, the following analysis explores youthful spatial attachments related to familial life as topologically established and topographically conditioned. 
The home is appreciated as a familial space that emerges, transmutes, and shifts through significant socio-spatial associations in the ebb and flow of everyday life where children and young people are situated subjects who, within conceivable limits, participate in the constitution of this space in connection with other people (cf. Smith, 2005; Noble, 2009). 'Topological home' hence denotes an intersubjectively established and mutually shared lived space of the family (whomever it may include), existing particularly to each of its members through subjective engagements. It is identifiable by the people who share it but has no singular or enduring shape because the subject is an elemental part of its constellation (Blum and Secor, 2011; Secor, 2013). Thus understood, homes can be located only partially on Euclidean maps. Better than that, the shifting and multiform presence of topological homes can be traced from the relational spatial attachments that people create and cherish in their familial lives.

To bring in the political element, I find this understanding of spatiality compatible with Hannah Arendt's thinking on situated political life that uses a phenomenologically oriented perspective. In her posthumously published manuscript Introduction into Politics, intended as a continuation to Human Condition but left incomplete, she states: "If someone wants to see and experience the world as it 'really' is, he can do so only by understanding it as something that is shared by many people, lies between them, showing itself differently to each and comprehensibly only to the extent that many people can talk about it and exchange their opinions and perspectives with one another, over against another.” (Arendt, 2005, p.128). This understanding of spatial situatedness leads to a relational notion of politics.

To Arendt (2005, p.96, 1958, pp.7-21), politics is about living together in a world of plurality where people possess the capacity to begin new things. By relating actively with each other, and acknowledging relative differences and relative equalities within the given community as a 
starting point of this activity, people may uphold democracy as a live principle. Indeed, leaning on a Simmelian conception of individuality (see Pyyhtinen, 2008), Arendt (1958, p.8) argues that people relate to one another in two ways: firstly, by relative difference, which refers to categorical difference/similarity defined by social status and actualizing in identity constructions; secondly, by relative uniqueness, which means that "we are all the same, that is, human, in such a way that nobody is ever the same as anyone else who lived, lives, or will live”. The idea of plurality hence accepts that communities are always traversed by more or less uneven relations between individuals and collectives and contain disparities and inequalities. The uniqueness of subjectivity, instead, is that which provides for the human capacity to create 'beginnings', i.e. bring about change.

Arendt conceives human agency as being political when it seeks to challenge the status quo and transform power relations. Whereas she links politics irremovably with matters of the State and collective practice (quite understandable in the post-WWII period), in the light of contemporary political and spatial theories politics can be interpreted more broadly to include private matters and individual acts and transnational and translocal communities (Dikeç, 2013; Isin, 2012). The politics of living together in the topological home can, then, be traced from the ways in which people act for and against matters that are important to them in their familial lives, which may acquire relevance in any scalar dimension and be connected with various other spheres of life (Häkli and Kallio, 2014, also feminist tradition as discussed in the introduction). This interpretation acknowledges also children's potential for political agency as family members, which arises in engagements and struggles that affect the geographies of their homes (Bosco, 2010; Bartos, 2012; Mashall, 2013; Aitken, 2014). 


\section{Youthful situated agency and the constitution of 'home'}

The idea of home as an intersubjectively constituted lived space designates that, from the moment of birth, children are active agents in the socio-spatial processes of familial meaning making (Barrett, 2003, p.201; Kjørholt, 2007, p.39). Through their innumerable everyday encounters with people, things and issues, children make sense of and locate their home from their particular position, at once placing themselves and other people in the emerging constellation "landscape[ing] their world differently in terms of both locale and relations" (Latimer and Munro, 2009, p.327). The situated knowledge constituted in this process is directed by 'banal socialization' that is rooted in the practice of familial life with multiple more and less explicit underpinnings, directions and aims (cf. Katz, 2006; Haldrup et al., 2006; Slavtcheva-Petkova and Mihelj, 2013; Kallio, 2014a). Paraphrasing Secor (2013, p.440) "the [home] in this argument is not simply 'subjective', something that each person has his/her own version of [...] the [home] and the subject are distributed, splayed out, a Möbius surface that encircles its own limit”.

The dynamic of this complex process is aptly captured by Sherry Ortner’s (2006, pp.127-153) practice-theory-informed concept of “serious games” that is helpful in identifying youthful political subjects in the topological home. The basic idea comes close to Arendt's seemingly simple idea about living together: By viewing active human agents as being socially embedded simultaneously in the relations of solidarity and those of power, inequality and competition, Ortner (2006, p.130) pictures an ongoing dynamic where the micro-politics of everyday living enmesh with the "larger forces, formations, and transformations of social life" (cf. Philo and Smith, 2003; Mitchell and Elwood, 2013). In a Butlerian spirit, she considers that since differently scaled institutional and mundane structures and conventions pre-exist a child's 
emergence, the lived worlds that children enter involve plenty of deep-rooted matters that are introduced to them in the form of subject positions (cf. Elwood and Mitchell, 2012).

To acquire a part in the 'family game', children need to create a character by which to play along with the rules. Ortner stresses that these roles are not merely given but actively taken, which means that also the rules of the game may be challenged by averting the proposed subject positions. By attaining particular roles in their families children can hence shift the geographies of their home to better fit their conceptions. In this perspective, "home can be taken to be the place wherein self finds itself most comfortably situated [...] as a site of routes [rather than] habitation in the form of roots” (Latimer and Munro, 2009, p.319, p.326). The bottom line in Ortner's argument is that people cannot exist beyond serious games, which, again, are dependent on human agency. She therefore emphasizes that every game is continually actively practiced by its participants (cf. political subjectivity in the politics of recognition, e.g. Fraser, 2000; McNay, 2008; Häkli and Kallio, 2014).

This understanding of situated subjectivity, instilled in the framework of the topological home and the politics of living together, informs the following empirical analysis that traces personally conceived and mutually shared relational homes where children perform as active agents. Before turning to the analysis, I will introduce the study and its methodological approach.

\section{Exploring topological homes}

Topology is a highly theoretical concept, which is often discussed about more ontologically than empirically. There are studies that have set out to trace the topologies of different phenomena in practical research settings, such as in concentration camps (Giaccaria and Minca, 2011), urban landscapes (Harker, 2014), practices of care (Milligan et al., 2010), and popular geopolitical 
imagery (Rech, 2014). In each case, the exploration contains a constant balancing act between the complex topological imagination and the banal practice of everyday life, which are not an easy couple to marry. To accomplish this, it is necessary to strip topology of some of its multifarious dimensions and concentrate on certain facets that seem particularly pertinent in the studied case so as to allow a somewhat coherent analysis. This means that some fine-tuned theoretical elements are lost, unless the case is selected particularly to illustrate the theoretical imagination (e.g. Blum and Secor, 2011; Giaccaria and Minca, 2011). The study discussed in this paper is strongly empirically focused, which tilts the analysis toward a compromise. It provides a modest attempt to understand certain dynamics of the lived world in topological terms.

\section{Locating experiential worlds with children}

Children often express their understandings in the form of affective and metaphoric expressions, instead of rationalized verbal conceptions (e.g. Katz, 2004; Marshall, 2013; for similar notions on fieldwork with adults, see Rose, 1997; Kuusisto-Arponen, 2009). Multiple empirical research methods are therefore needed to gain access to their experiential worlds. Following a methodological approach inspired by Sherry Ortner’s (2002) critical documentary ethnography, my study involved mapping and storytelling exercises accompanied by informal individual interviews. The collected materials resulted in place-based dialogical biographies. ${ }^{i i}$ These are not full biographies but rather contextually created partial accounts on one’s spatial embeddedness and situated subjectivity, which are suitable for "scaling from below" (Nielsen and Simonsen, 2003). Through the cross-references that our participants made in the interviews, I learned how their biographies are also biased as certain issues and perspectives were brought into the discussion less eagerly than others. While such partiality and bias is problematic, it is something 
ethnographers must just live with, as Rose (1997) and others have vividly professed. Instead of looking for missing things and shortcomings, the analysis thus focuses on what is there and accepts that all situated knowledge is partial.

The fieldwork was carried out in 2012 by myself and my colleague Elina Stenvall in Helsinki and Tampere, Finland. We engaged with four elementary and three high school classes involving 74 fifth graders (11/12-year-olds) and 55 ninth graders (15/16-year-olds). In this paper I focus particularly on the fifth graders who can be considered more clearly 'children' in their families than the ninth graders. The selection of research sites was informed by my working hypothesis, which proposed that even in the most 'ordinary' school classes there are notable differences between children's experiential worlds and respectively their political agencies. We hence chose schools where socio-economic, ethnic, and other differences are not striking or notably biased. The mapping platforms were generated from the Google Maps web mapping service application that served our purposes in three ways. First, the format was familiar to our participants, which facilitated the mapping exercise. Second, as this service does not provide very precise maps or highlight places by certain hierarchies (e.g. population, geopolitical relevance, historical status), the platforms imply correctly that the exercise does not aim at precision or testing of know-how but instead invites the participants to map their experiential worlds. Third, the service allows the user to choose the map boundaries freely. This helped us to create the kinds of platforms that we found suitable for the exercise. We created six differently scaled platforms that provided opportunities for locating lived realities in the 'World', 'Continent', 'State, 'Region', 'City', and 'Neighborhood'

In all fieldwork, an ethical research practice ${ }^{\mathrm{iii}}$ was followed, which in particular appreciated our young participants' right to decide whether they wish to get involved with the study or not. 
Practically, we did this by letting them choose what they do and do not want to share with us. The only instructions they were given at the beginning of the mapping exercise were:

This study provides you the opportunity to tell us about your world; what things, places and people are important and interesting in it. They may be to your liking, important just because they are an inseparable part of your life, or you may fear or dislike them.

In creating their maps the participants could use three colors to signal different associations: pleasant (green), neutral (yellow), and unpleasant (red). The thus generated maps served as personified interview structures; all discussions were based on these markings, and they expanded in directions in which each child wanted to lead us.

The fieldwork resulted in the desired outcomes in both ethical and substantial terms. The folders where all collected materials are individually stored range from virtually empty ones to rich data sets. We hence received a good amount of empirical material and found our ethical efforts were met - the children whom we invited to our study apparently felt that they could participate according to their will. Moreover, the materials and the results can be considered particularly child-centered as all discussed themes and spotted locations were initiated by our participants. Questions we posed in the interviews to open up the discussion avoided any substantial and spatial hints and included for example: "You have a green/yellow/red marking here, do you want to tell us why it is there and what it is about?”. The biographies hence emphasize aspects of our participants' choosing. Among the most popular themes and spatial dimension that they took up were 'the familial' and 'the home', which led me to analyze them indepth. 


\section{Accessing topological relations through home}

As the home signifies a self-evidently important context of living to most people, it was not surprising that many of our participants commenced the dialectic production of their place-based biographies there. Nearly all had spontaneously marked their familial places of importance on the mapping platforms and introduced them together with their family members in the interview. Most were residents in the neighborhood surrounding the targeted school, which provided certain common topographical conditions to their lived worlds. However, the conveyed spatial attachments were still anything but uniform. Whereas some marked their familial life clearly at one spot - usually the address where they lived - others introduced several sites of familial importance. All mapping platforms implying different scalar dimensions were used in this purpose.

An extreme example of widespread familial spatial attachments was presented by Robin, a boy who used all of his 100 yellow sticky notes, plus some green and red ones, to plot the places where he had been to with his family. One by one, we followed his marks from the world map to the continental, national, regional, local, and neighborhood map. He gave us short descriptions of each mark indicating his relationship with the place. These range from great adventures and cozy hotels to 'average' resorts and boring and displeasing sites. As we finally ended up at the neighborhood map, the following conversation occurred:

Interviewer: Then there is another 'ok' place?

Robin: Home.

Interviewer: Home, why is it 'ok'? 
Robin: Well because... it’s like... I don’t spend much time there and then again nothing much happens there because I am not there so much.

To Robyn, the physical house and home of the family appeared as the least significant familial site. This notion was emphasized by his perception about the nicest thing related to travelling: "Spending relaxed time with the family, a lot.” These findings were quite unexpected as he is 12 years old, his parents are primary school teachers, and they live in a middle-class area of a middle-sized North European city. Yet we realized that if this is the way the home exists to him, as a self-evident context of living, it must be considered as such in the analysis, too.

Robin's case is rather exceptional, but it draws attention rightly to the multiplicity and unpredictability of familial spatial attachments. Even if practically all of our participants introduced their homes to us, we did not encounter two similar experiential spaces of dwelling not even in the case of identical twins. Home can hence be considered a generally significant and particularly meaningful context of living, not only for children but also more broadly.

Many of our participants told about the intensive family time during their vacations, when various places which were visited became special to them. These included summer cottages, winter cabins, grandparents' homes, holiday resorts, recreation areas, cruisers, and other places where they had spent time with their close and extended families, sometimes accompanied by personal and family friends. Moreover, different kinds of mundane environments (e.g. mother's, father's, grandparents', sibling's, aunt's, uncle's, neighbor's homes and workplaces), as well as memorized and imagined places (e.g. previous homes, places where they have family but no visiting history, places of origin with existing or lost family members), were mentioned as being important family-wise. This spatio-temporal variation is revealing in regard to the topological 
familial life in a way that cannot be attained through cartographic expressions alone; instead it necessitates experiential disentanglement.

In Robin's case, it is easy to grasp how his home is not fixed in one place but instead consists of shifting spatial attachments, including lasting elements such as 'hotel room', 'restaurant dinner', 'daunting challenge', 'airplane', 'walk in the city', and so forth, that make him feel at home. When a person's everyday routines are repetitive and take place mostly around the family house, the challenge of accessing the topologies of one's home increases. In some people's lives topographical conditions influence more strongly the organization of daily practice, making certain people, things, and places close by appear as particularly important and comfortable. Yet even then it is not the distance per se that defines the importance but the signified proximity that may, as Latimer and Munro (2009) argue, expand in all kinds of directions through spatial and temporal extensions that are not visible to a hasty eye.

One of Robyn's classmates, Rasmus, portrayed this kind of a lived world. He has little experience of traveling overall, and the only familial associations he mentioned outside of his hometown are his grandparents' places that he visits randomly with his parents. Rasmus' life is mostly located in the neighborhood where he lives with his parents, their dog, and his school buddies. Still, his biography contains many particular spatial attachments. As we interviewed 68 kids living in this area, I am rather familiar with the places where children and young people may and do spend time. Most of these do not appear in Rasmus' biography, at least not in the typical way. For instance, the local pizzeria that is popular among his classmates is not marked at all. Instead, a much more modest, old-fashioned fast food stand at the fringes of the area is located with green color. Another peculiarity is the green-marked local pond that regularly appears as red 
on our participants' maps. It is considered unpleasant by others due to its dirtiness and is usually associated with particular school activities.

Explanations for these distinct markings are familial. The fast food stand is a place where Rasmus’ father sometimes takes him for a snack. In describing this place he uses an oldfashioned term for burger, and in doing so emphasizes a familial and not a peer cultural affiliation. The local pond is introduced as a place to go with the dog. Walking the dog is another activity associated with his father; one that involves dropping by at a local shop on these trips. This shop was regularly mentioned by our participants as being a venue with a strong peer cultural affiliation as it is a common place to buy sweets after school. Yet to Rasmus it has a different function. The untrendy fast food stand, the child-avoided puddle, and the local food store are places that Rasmus, his father, and their dog have signified together as sites where their familial life takes place.

This example seeks to indicate that when associations enabled by physical proximity become particularly important they are subjectively generated and, at least in the case of the home, intersubjectively established. These meaning making processes are constitutive of topological relations. On the contrary, if the subjective bond is not formed, the topographical spatial relations remain dominant and the distance in Euclidian space is defining. To Rasmus, for instance, the close-by pizzeria is a close-by pizzeria providing a local service conveniently at hand if needed. Unlike the preferred fast food stand, it does not involve him as a familial subject and therefore plays no role in his constitution of home.

To summarize, accessing people’s topological realities entails setting aside the aspect of physical distance and finding out about "what it is that [they] care for” (Latimer and Munro, 2009, p.324; also Bartos, 2012). This methodological means, even if perhaps simplifying and 
limited, has proven useful in my study where lived worlds do not divide neatly into apparent spatial spheres but unfold as a mishmash of everyday life.

\section{The shared and subjective home}

Spatial bonds can be ethnographically identified from specific experiences, cherished memories, frequency of expressions, anticipations and imaginings, particularity of people and places, and so forth. Marshall (2013) suggests affectivity as one key aspect in analyzing these engagements (also Dyck, 2005; Muños González, 2005), and Bartos (2012, 2013) points to the significance of enmeshed intergenerational and peer relations (also Vanderbeck, 2007; Bosco, 2010; Bunnell et al. 2012; Kallio, 2014b). In my study I have found both insights relevant, which becomes apparent in the following analysis where I have selected the case of Milla as being illustrative of the particularity of familial subjectivity and spatial attachments.

The owner of the biography, Milla, is another fifth grader who lives close to the school together with her father, mother, and elder sister. In the mapping exercise she colored their house both green and red. The previous refers to her friends living next door and the latter to her "sister who teases". Compared with the yellow label on the school - "sometimes nice, sometimes boring” - her expressions concerning the home are very affectionate. This emotional charge was helpful in identifying her particular familial situatedness.

Milla's notions concerning her sister have a negative tone throughout the biography. You first hear how "she claims that I have done something even if I have not, or then she is just like nasty when she starts to shout”. When asked whether they ever have a good time together she answers "yes, when she is in a good mood", making it evident that Milla finds herself a weaker player in their relationship. A partial explanation for the strained relations is surely that the sisters spend a 
lot of time at the house by themselves. Their mother works late and does not have long vacations, and the father apparently keeps to himself when not at work, as his presence does not seem to affect the situation. In addition, the fact that, unlike most of her friends, Milla is not allowed to move about on her own beyond the neighborhood means that she and her sister spend plenty of time together in the family house.

But there are other reasons, too. Milla conveys that the sisters appreciate different kinds of people, things, and places, and have distinct priorities when it comes to their free time and activities. When they travel to their cousins' house, her sister does not like to spend time with them because "she does not care for hide-and-seek or such anymore". Age plays no role here: "Even though [the cousins] are four years older than me ... we always find fun things to do.” Similarly, when they visit their family friends who have three girls of their age, or their grandmother's place, the sister often “can't make it” due to her hobbies or some other reason. In all these places Milla enjoys herself tremendously, describing them as "the best people and times in the world".

Milla’s affectionate familial relationships became ever more apparent as we passed through the large-scale maps. On the global platform, she had marked China green because her "best friend" was adopted from there. She uses this expression only once in the whole lengthy interview that introduces a number of dear friends, implying that their friendship is truly something special. It is part of an enduring relationship between two families who live a couple of hours away from each other and pay regular visits. Also certain places far north and down south at the national platform are marked as important locations on account of annual holidays that are shared with two more 'friend families ${ }^{\text {'iv }}$. While these families do not have children of Milla's age, it is still the people that make the places special. She gives no details about the things 
she enjoys there but instead says that "it is always fun there because also our friend family is there" and "it is nice to be there because there is a young boy there and he is fun in a way". Moreover, 'there' does not refer to the same physical location each time: For instance, the 'cabin in the north' refers to any cabin they may rent together within the skiing region.

These socio-spatial attachments, parallel to those identified by Bartos (2012, 2013; see also Bunnell et al., 2012 on friendship) with children of approximately the same age in rural New Zealand, are only emphasized by Milla's account of her distant grandmother's place. When explaining the green color she says: "It is nice to go there because my friend has come along two times when my sister has not felt like it.” In the storytelling exercise, Milla chooses to tell more about these trips; she describes their specialty and joyfulness with particularized portrayals that are filled with superlatives and exclamation marks and pays no attention to distance. Also this spatial attachment is strongly based on sharing and deliberately connects one of Milla's personal friends with her family in a way that has helped her to uphold the intergenerational familial ties; ties her sister feels less affectionate about and is thus not ready to actively maintain. As kith turns to kin in the two girls' relationship, the familial bond attached to the grandmother's place bolsters and changes shape in Milla's topological home.

The discussed case provides one example of how the home as a space of dwelling is "made, [involving] the potential for changing subjectivities-or ways of 'being in the world'-of individual family members” (Dyck, 2005, p.241, 239). The biography stresses dissimilarity in Milla’s and her sister's experiential familial attachments and subjectivities: Even if they spend plenty of time together, their 'familiality' diverges from one another's remarkably. This means that as particularly situated subjects who are active in the constitution of their lived worlds the sisters share much of their daily life in the family house but lead their lives in rather different kinds of 
homes. As Milla's home is intersubjectively established in the mundane familial practice, yet exists to each individual member through experiences that extend the lived home beyond its apparent sites and locations, her topological home takes the form of a twisted coil that inseparably intertwines the subject and the site (Secor, 2013, p.438). Thus appreciated, it forms a relational basis and arena for influential familial agency.

\section{Children's efficacious familial agencies}

Children participate in the constitution of their everyday contexts of living as situated subjects whose perceptions associate, but which do not necessarily affiliate, with the views of the other people involved. In an Arendtian reading, these acts turn political when they set out to challenge the status quo or to transform power relations. In my study such agencies were not typically discussed as intentional practices but instead as subtle maneuvers that both influenced my participants' politics of living together in their mundane communities and affected their political subjectivities on a grounding level. This section introduces some ways in which children act to maintain, repair, reconstruct, and challenge their homes by drawing on two empirical cases.

The first example comes from Milla's case, leaning on the subtext provided in the preceding section. Her biography includes a portrayal of a familial struggle over her hobby, ballet, that she wanted to change for a more relaxed one. Without going into too many details, the core of the argument was that her parents wanted Milla to continue with ballet because they had gone through the same dilemma with their elder daughter, who in the end continued with ballet and was later happy with the decision. This parental attitude had felt not only wrong but also offending to Milla. From the way she portrayed the events to us it can be construed that the argument, which was seemingly about the hobby, involved her eminently as a familial subject. 
The question was not only if she should or should not continue this hobby but, rather, if she should continue the hobby like her sister or change it for a different one as herself.

Besides her parents' objection, Milla found it particularly difficult to accept the paralleling they made. How could her sister’s experience be used to measure her situation, as they are completely different kinds of people? Like Latimer and Munro (2009, p.327) explain, “The argument is not so much that one form of living is superior to the other, as it is the case that the one kind of dwelling includes what the other leaves out.” Milla had used plenty of effort to convey to her parents what she does not like about ballet in order to avoid symbolic subordination and to improve her position. Moreover, she had stressed that her stance was based on long-term consideration and requested that her decision be considered a 'thoughtful act' in its own right (cf. Kallio, 2014b). These efforts were successful. Finally, her parents were convinced that their daughters' cases ought not to be paralleled and that she should be allowed to change her hobby if she felt like it.

In this situation where the parents came to evaluate their daughters' differing priorities over dwelling, first (probably unintentionally) in favor of the older sister and then from a more pluralistic perspective, Milla accomplished two things. First, her particular subjectivity as situated in the topological home received recognition. As the parents admitted that she is not like her sister but a person in her own right, with subjective ways of experiencing things and the ability to form opinions on that basis, they acknowledged her relative uniqueness (on the politics of intergeneration recognition, see Noble, 2009; Kallio, 2014b). Following Arendt, Milla was regarded as someone who is not "the same as anyone else who lived, lives, or will live" (see section two, p.x). This subjective 'who-ness' is the premise of the human condition that enables political life (Häkli and Kallio, 2014, p.188). The events can therefore be considered significant 
to her existence as a political subject. Second, Milla’s persistent agency succeeded in challenging the intergenerational power relations by which her family operates. In their 'serious games' where relations of solidarity co-exist with those of power, inequality, and competition (see section three in this article, p.x), she refused to adopt the subject position of the 'second daughter’. Instead, she negotiated a more distinct familial role that she could adopt, one not formed in relation to her sister. From this perspective, her agency can be seen as political also in the here and now.

The reason why Milla discussed this incident so intensely with us was apparently its manifold importance to her as a political subject. This importance can be noticed on a very grounding level; on the one hand in relation to her political subjectivity and on the other hand as unfolding in the power-dynamics of their home. The previous can be considered particularly significant in regard to her 'political becoming' (Spyrou, 2006; Payne, 2010), whereas the latter professes about her 'political being' (Lister, 2008; Wood, 2012).

The second example sheds light on children's active familial political roles from a slightly different direction. It derives from a case of Liisa and Marja, two fifth grade twin girls whom I interviewed twice during the study. If you look at their maps knowing that they are twins, you can easily spot similarities. Yet when I interviewed them, this was not the case. As mentioned in the study description (p.x), the idea of our research was to allow the participants to choose what they do and do not want to share with us. Hence, we did not ask for surnames or any other identifiers that were not spontaneously delivered. Since Liisa’s and Marja’s biographies differ notably, especially with reference to the home, I did not realize their sisterhood during the interviews.

Liisa’s biography portrays a family where the parents are recently divorced. Her mother continues to live with the children in the family house close by the school, and her father has 
moved to the countryside into his childhood home, which is nearby the city but too far to be visited independently by the children. He meets them weekly at their mother's place, and they stay at his place regularly during the weekends and holidays. Having learned this, it seemed understandable why Liisa discussed the life she shared with her mother extensively and underlined their close relationship. Liisa, for instance, accentuated that she always picks her up from her hobby, which also forms a matter of mutual interest to them. She even marked her mother's workplace and the health club where she goes. All this implies that matters related to her mother feel particularly important to her. This is emphasized by the fact that her father appears in the biography only as the 'visiting parent'.

In Marja’s biography there are no signals of separated familial life. She discusses her siblings, grandparents, neighbors, and other family members quite like Liisa, but the father's house does not appear in the maps or surface in the interviews. Yet she introduces him much more thoroughly and proudly than Liisa. Marja's father is a musician who both teaches and performs the saxophone. She has marked down places where he works and plays but, in contrast, makes no mention of her mother's working life or free time activities. Marja also conveys that he picks her up from her hobby two to three times per week and often goes to watch the training practices as he greatly values her skill in gymnastics.

As I realized that Liisa and Marja are twin sisters, it became noticeable that the mapping exercise had provided both girls with the opportunity to articulate their familial lives subjectively, bringing up things, people, and places as they are important to them. My interpretation is that they did not describe their homes to us but constituted them intersubjectively with us. This is not only interesting for the analysis, but also methodologically. In these and some other cases our fieldwork came unintentionally close to participatory action research. Cahill (2007) presents that 
the core idea in this approach is engaging with the participants in an empowering way, with potential ramifications to their lived realities. It therefore seems that a committed child-centered approach in itself may be empowering if the participants are eager to use the opportunity. Yet the kind of methods we used provide the participants also the opportunity not to get engaged in these ways, which respects their rights as voluntary research participants (on 'less participatory' methodological approaches, see Kallio, 2012).

In this process of dialogical 'home creation', Liisa and Marja adjusted themselves as familial subjects into the evolving constellations of their homes in ways comfortable to them. Liisa portrays straightforwardly their newly-established familial life, discussing her mother and herself as its central figures. Marja, instead, makes no effort to correct our presumption that they all live in the same house and emphasizes the relationship with her father as particularly close and important. A common context for the actualization of these relationships is the hobbies through which the girls divide the family into child-parent couples. They have both marked down the sports halls where their hobbies take place, thus acknowledging each other's presence. Yet in the biographies, the sister is never picked up and her performance does not interest anyone.

As the other child-parent couple is practically missing from the stage, the topologies of the girls' homes become quite dissimilarly shaped. As in Milla's case, also this one reveals much about the particularity of experiential spatial relations. Liisa's and Marja's biographies are guided by subjective understandings of home that they expressed in our dialogical research process, performing actively as familial subjects. Presumably, they sought to contribute to the reconstitution of their homes also in other mundane encounters as their familial lives were forcefully seeking new forms at the time of our study. This activity, informed by their political 
subjectivities, can be regarded as attempts to shift the geographies of their homes in desirable directions.

Moreover, by narrating their families in particular ways, the girls made explicit that building home anew is a collective process that involves struggles over its meanings. Even if unintentional, these processes may bolster familial inequalities. Some developing trajectories can be identified from their biographies. For instance, when Liisa describes their father's role as rather distant and introduces Marja explicitly as “daddy’s girl”, she implies that also her position in the family is weakened in the new situation. Her own position as “mommy's girl”, instead, appears to have been strengthened by the divorce, which provides her confidence for the future. Supporting this interpretation, Marja's biography implicitly implies a meager faith in the future of her family. She portrays their father as indivisible from her familial life, and thus from herself, which makes her topological home contested in the present situation.

Like in Milla's case, the political relevance of Liisa's and Marja's agencies is of a fundamental nature. Their practical efficaciousness in the constitution of their homes is hence hard to demonstrate. What the analysis does make visible is that the power of articulation, as discussed by Mitchell and Elwood (2012), may be harnessed also by children who are capable of involving adults in their political processes. Liisa and Marja used our study for their own ends to portray how they are splayed out on the Möbius surface of their homes. It was these topological homes that were introduced to us in the interviews and that drew my attention forcefully away from the topographical similarities of their maps. How I came to know the girls in the first place is, therefore, proof about their active roles in renegotiating their familial lives: By succeeding to assure me that they live in completely different worlds they involved me as a participant in their mundane politics. 
The two examples in this section have striven to demonstrate how youthful agency may play out in the familial politics of living together. They portray topologies where the subject and the home are inseparable and are thus always concurrently affected by the events of familial importance where Milla, Liisa, and Marja took active roles. The geographical shifts that follow from such activities are unpredictable. They may lead to new intensities in familial practice; Milla's family may find more time to spend with their 'friend families', and Liisa's and Marja's parents may start to divide their responsibilities related to the girls even further. They may also motivate physical movement; perhaps Marja’s father will move back to the city and Milla’s grandmother will find a place to live closer to their house. The children's activities may also generate changing power dynamics in their families; it is possible that Liisa and Marja become increasingly opposed in their familial lives, and Milla's parents can start taking her views better into account in the future. Yet human life is much too complicated for addressing such causeeffect relations. What can be identified, instead, are the potentially efficacious agencies that evolve political subjectivities and subjective spatial attachments.

\section{Topological home as a formative milieu of living together}

This article has made a theoretical and an empirical argument concerning the home as a context

of everyday politics. Bridging relational spatial theorization with Arendt's political philosophical thought and Ortner's practice theoretical insights, it proposes a topological conception of home. In this view, home is an intersubjectively established and mutually shared lived space of the family that exists in a particular way to its members. Topological home is identifiable by the people who share it but has no singular or enduring shape because the subjects who are involved in the familial life are elemental parts of its constellation. By and large, the paper aims at building 
an approach along the lines of Secor (2013, p.436) that "can both help us work through the ontological or metaphoric status of topology and bring questions of subjectivity into conversation with spatial theory".

Empirically, I have explored the home as a venue of living together for its youthful members who act from subjective stances to maintain, repair, reconstruct, and challenge their familial relations and realities. I have considered these practices as being political when they set out to challenge the status quo or to transform power relations. The analysis seeks to make visible that home is a particular context of living for each person involved in a given familial life, including children who participate in the constitution of their topologies through various means. I have specifically sought to display how children are 'splayed out' in their topological homes as political subjects, which means that their subjectivities are inseparable from their experiential homes.

In conclusion I suggest that instead of a static physical spot that can be placed on a map and located by a street address and a postal code, home should be understood as variable in form, practice, and extension. Familial lives are constituted by people of kith and kin from diverse generational positions, and they include animal, natural, and material elements that are meaningful to the people involved. As experiential lived spaces, topological homes may unfold basically anywhere - in places near and far, as well as in networked and fluid spatial dimensions. Their spatial attachments may shift from place to place with the people who lead their familial lives together but also remain tightly set in specific locations that have gained particular importance in these homes. Moreover, as a playground of serious games and a mundane context for the politics of living together, home is constantly re-constituted and -located by its dwellers. Family members are bound by relations of solidarity as well as those of power, inequality, and 
competition, which lead to constant negotiations and struggles concerning familial life. These are not only constitutive of the home as a context of living but importantly also the people as political subjects who are constantly in a state of becoming.

As a final conclusion, I wish to propose that just as the city can be understood as a difference machine that produces citizenship, as portrayed by Engin Isin (2002) in his genealogical exploration of the democratic society, in an Arendtian perspective the home can be appreciated as a 'difference and equality machine'. In their familial lives people not only relate to one another in regard to their socially constituted identities (defined by age, gender, birth order, generational position, etc.) but also as unique individuals who are not comparable along certain attributes (e.g. Milla, Liisa and Marja as particular individuals). In so doing they come to reshape each other's political subjectivities that form the condition of possibility of their political agencies. With intersubjectivity and intergenerationality as its modus operandi, this machine plays a major role in (children’s) 'political becoming' and 'political being', which makes the home one of the major milieus of political subject formation.

\section{Acknowledgements}

I am grateful to the editors of Space and Culture and to the anonymous referees for their engaged and helpful comments and suggestions. I also wish to thank the Academy of Finland for financially supporting this work (grants SA258341, SA134949), and the University of Tampere Space and Political Agency Research Group (SPARG-RELATE) and the Durham University Geography Department for inspiring research environments. Special thanks to Elina Stenvall for the fieldwork and to Anna Secor for the encouraging comments. 


\section{References}

Abel, E., \& Nelson, M. (Eds.). (1990). Circles of Care: Work and Identity in Women's Lives. New York, NY: State University of New York.

Aitken, S. (2014). The Ethnopoetics of Space and Transformation: Young People’s Engagement, Activism and Aesthetics. Farnham: Ashgate.

Allen, J. (2011). Making space for topology. Dialogues in Human Geography, 1, 316-318.

Amin, A. (2004). Regions unbound: Towards a new politics of place. Geografiska Annaler: Series B, Human Geography, 86, 33-44.

Arendt, H. (1958). The Human Condition. Chicago, IL: University of Chicago Press.

Arendt, H. (2005). The Promise of Politics. (J. Krohn, Ed.). New York, NY: Schocken Books.

Barker, J. (2012). A free for all? Scale and young people's participation in UK transport planning. In P. Kraftl, J. Horton, \& F. Tucker (Eds.), Critical Geographies of Childhood and Youth (pp. 169-184). Bristol, England: Polity Press.

Bar-On, A. (1997). Criminalising survival: images and reality of street children. Journal of Social Policy, 26, 63-78.

Barrett, M. (2003). Meme engineers: children as producers of musical culture. International Journal of Early Years Education, 11, 195-212.

Bartos, A.E. (2012). Children caring for their worlds: the politics of care and childhood. Political Geography, 31, 131-194.

Bartos, A.E. (2013). Friendship and environmental politics in childhood. Space and Polity, 17, 17-32. 
Berrick, J. D., Courtney, M., \& Barth, R. P. (1993). Specialized foster care and group home care: Similarities and differences in the characteristics of children in care. Children and Youth Services Review, 15, 453-473.

Bosco, F. (2010). Play, work or activism? Broadening the connections between political and children’s geographies. Children’s Geographies, 8, 381-390.

Bunnell, T., Yea, S., Peake, L., Skelton, T., \& Smith, M. (2012). Geographies of friendships. Progress in Human Geography, 36, 490-507.

Cahill, C. (2007). The personal is political: Developing new subjectivities through participatory action research. Gender, Place \& Culture: A Journal of Feminist Geography, 14, 267-292.

Desforges, L., Jones, R. \& Woods, M. (2005). New geographies of citizenship. Citizenship Studies 9, 439-451.

Dikeç, M. (2013). Beginners and equals: political subjectivity in Arendt and Rancière. Transactions of the Institute of British Geographers, 38, 78-90.

Dyck, I. (2005). Feminist geography, the ‘eveyday’, and local-global relations: hidden spaces of place-making. Canadian Geographer, 49, 233-243.

Elwood, S., \& Mitchell, K. (2012). Mapping children’s politics: spatial stories, dialogic relations and political formation. Geografiska Annaler: Series B, Human Geography, 94, 1-15.

Fraser, N. (2000). Rethinking recognition. New Left Review, 3, 107-120.

Giaccaria, P., \& Minca, C. (2011). Topographies/topologies of the camp: Auschwitz as a spatial threshold. Political Geography, 30, 3-12.

Häkli, J. (2008). Regions, networks and fluidity in the Finnish nation-state. National Identities, 10, 5-22. 
Häkli, J., \& Kallio, K.P. (2014). Subject, action and polis: Theorizing political agency. Progress in Human Geography, 38, 181-200.

Haldrup, M., Koefoed, L., \& Simonsen, K. (2006). Practical orientalism: Bodies, everyday life and the construction of otherness. Geografiska Annaler Series B: Human Geography, 88, 173-184.

Harker, C. (2014). The Only Way Is Up? Ordinary Topologies of Ramallah. International Journal of Urban and Regional Research, 38, 318-335.

Isin, E. (2002). Being Political: Genealogies of Citizenship. Minneapolis, MN: University of Minnesota Press.

Isin, E. (2012). Citizens Without Frontiers. London, UK: Bloomsbury Academic.

Kallio, K.P. (2012). Desubjugating childhoods by listening to the child's voice and childhoods at play. ACME: An International E-Journal for Critical Geographies, 11, 81-109.

Kallio, K.P. (2014a). Rethinking spatial socialization as a dynamic and relational process of political becoming. Global Studies of Childhood 4, 210-223.

Kallio, K.P. (2014b). Intergenerational recognition as political practice. In R. Vanderbeck \& N. Worth (Eds.), Intergenerational Space (pp.139-154). London: Routledge.

Katz, C. (2004). Growing Up Global: Economic Restructuring and Children's Everyday Lives. Minneapolis, MN: University of Minnesota Press.

Katz, C. (2006). Banal terrorism: Spatial fetishism and everyday insecurity. In D. Gregory, \& A. Pred (Eds.), Violent Geographies: Fear, Terror, and Political Violence (pp.349-61). New York, NY: Routledge.

Kjørholt, A.T. (2007). Childhood as a symbolic space: Searching for authentic voices on the era of globalization. Children's Geographies, 5, 29-42. 
Kullman, K. (2012). Experiments with moving children and digital cameras. Children's Geographies, 10, 1-16.

Kuusisto-Arponen, A.K. (2009). The mobilities of forced displacement: Commemorating Karelian evacuation in Finland. Social \& Cultural Geography, 10, 545-563.

Latimer, J. \& Munro, R. (2009). Keeping \& dwelling: relational extension, the idea of home, and Otherness. Space and Culture, 12, 317-331.

Lister, R. (2008). Investing in children and childhood: A new welfare policy paradigm and its implications. Comparative Social Research, 25, 383-408.

Lury, C. (2013). Topological sense-making: Walking the Mobius strip from cultural topology to topological culture. Space and Culture, 16, 128-132..

Marshall, S. (2013). All the beautiful things: trauma, aesthetics and the politics of Palestinian childhood. Space and Polity, 17, 53-75.

Martin, L., \& Secor, A. J. (2013). Towards a post-mathematical topology. Progress in Human Geography. [EarlyView]

Mason, J., \& Tipper, B. (2008). Being related. How children define and create kinship. Childhood, 15, 441-460.

McNay, L. (2008). Against Recognition. Cambridge, England: Polity Press.

Milligan, C., Mort, M. \& Roberts, C. (2010). From place to non-place? Locating new care technologies in the home. In M. Domenech \& M. Schillmeier (Eds) Care and the Art of Dwelling: Bodies, Technologies and Home (pp. 19-38). Aldershot: Ashgate.

Mitchell, K., \& Elwood, S. (2012). Mapping children's politics: The promise of articulation and the limits of nonrepresentational theory. Environment and Planning: Society and Space, 30, 788-804. 
Mitchell, K., \& Elwood, S. (2013). Intergenerational mapping and the cultural politics of memory. Space \& Polity, 17, 33-52.

Mitchell, K., Marston, S. and Katz, C. (2003). Introduction: Life’s work: An introduction, review, and critique. Antipode 35: 415-442.

Mol, A., \& Law, J. (1994). Regions, networks and fluids: Anaemia and social topology. Social Studies of Science, 24, 641-671.

Muños González, B. (2005). Topophilia and topophobia: The home as an evocative place of contradictory emotions. Space and Culture, 8, 193-213.

Nielsen, E. H., \& Simonsen, K. (2003). Scaling from 'below': Practices, strategies and urban spaces. European Planning Studies, 11, 911-927.

Noble, G. (2009). 'Countless acts of recognition': young men, ethnicity and the messiness of identities in everyday life. Social and Cultural Geography, 10, 875-891.

Ortner, S. (2002). Subjects and capital: A fragment of a documentary ethnography. Journal of Anthropology, 67, 9-32.

Ortner, S. (2006). Anthropology and Social Theory: Culture, Power, and the Acting Subject. Durham, England: Duke University Press.

Paasi, A. (2011). Geography, space and the re-emergence of topological thinking. Dialogues in Human Geography 1, 299-303.

Payne, P. (2010). Moral spaces, the struggle for an intergenerational environmental ethics and the social ecology of families: An 'other' form of environmental education. Environmental Education Research, 16. 209-231.

Philo, C., \& Smith, F. M. (Eds.). (2003). Political geographies of children and young people. Space \& Polity, 7, 99-212. 
Pyyhtinen, O. (2008). Ambiguous Individuality: Georg Simmel on the "who" and the "what" of the individual. Human Studies, 31, 279-298.

Rech, M. F. (2014). Be part of the story: a popular geopolitics of war comics aesthetics and Royal Air Force recruitment. Political Geography [EarlyView]

Rose, G. (1997). Situating knowledges: Positionality, reflexivity and other tactics. Progress in Human Geography, 21, 305-320.

Secor, A.J. (2013). Topological city. Urban Geography, 34, 430-444.

Shields, R. (1997). Flow as a new paradigm. Space and Culture, 1, 1-7.

Shields, R. (2013). Spatial Questions: Cultural Topologies and Social Spatialisation. Los Angeles, CA: Sage.

Slavtcheva-Petkova, V., \& Mihelj, S. (2013). Europe - a default or a dream? European identity formation among Bulgarian and English children. Ethnicities 13, 565-583.

Smith, M. (2005). Transnational Urbanism revisited. Journal of Ethnic and Migration Studies, $31,235-244$.

Spyrou, S. (2006). Children constructing ethnic identities in Cyprus. In Y. Papadakis, N. Peristianis, \& G. Welz (Eds.). Divided Cyprus: Modernity, History, and an Island in Conflict (pp. 121-139). Bloomington, IN: Indiana University Press.

Strandell, H. (2013). Mobile phones in children's after-school centres: Stretching of place and control. Mobilities [Published Online]

Thrift, N. (2006). Space. Theory, Culture \& Society, 23, 139-155.

Ursin, M. (2011). Wherever I lay my head is home'- young people's experience of home in the Brazilian street environment. Children's Geographies, 9, 221-234. 
Vanderbeck, R. (2007). Intergenerational geographies: Age relations, segregation and reengagements. Geography Compass, 1, 1-22.

Vanderbeck, R. (2008). Inner-city children, country summers: narrating American childhood and the geographies of whiteness. Environment and Planning A, 40, 1132-1150.

Wood, B. (2012). Crafted within liminal spaces: Young people’s everyday politics. Political Geography, 31, 337-346.

${ }^{i}$ Google Scholar search on author’s university-based computer, 26 May 2015.

ii Dialogical methodology traces back to Socrateian dialegesthai where finding out about the 'dokei moi', of how things appear to the other, is a starting point. This approach is pertinent to my phenomenologically oriented approach that is informed by Arendtian political philosophy (for details see Arendt 2005, pp.12-25).

iii We also sought informed consent from the participants' parents and acquired the necessary institutional research permissions. In the analysis, the specifics concerning the field work settings have been removed, and pseudonyms are used throughout.

iv 'Friend family' [ystäväperhe] is a concept commonly used in Finland that denotes a specific relationship between two families, which is mutually recognized and collectively established, i.e. it involves both families as multiagential. The concept exists in contrast to 'acquaintance family' [tuttavaperhe], which is another expression typically used to denote more remote family friends. It is obvious from Milla's narrative that she references the previous constellation. 